\title{
The patent internal thoracic artery graft: Increased degree of difficulty for left-sided pulmonary resections
}

\author{
Robbin G. Cohen, MD, MMM \\ From the Department of Surgery, Keck/USC School of Medicine, Healthcare Consultation Center II, \\ Los Angeles, Calif. \\ Disclosures: Author has nothing to disclose with regard to commercial support. \\ Received for publication June 11, 2015; accepted for publication June 12, 2015; available ahead of print Aug 5, \\ 2015. \\ Address for reprints: Robbin G. Cohen, MD, MMM, Keck/USC School of Medicine, Healthcare Consultation \\ Center II, 1520 San Pablo St, \#4300, Los Angeles, CA 90033 (E-mail: rcohen@usc.edu). \\ J Thorac Cardiovasc Surg 2015;150:536-7 \\ $0022-5223 / \$ 36.00$ \\ Copyright $(\underset{2}{ } 2015$ by The American Association for Thoracic Surgery \\ http://dx.doi.org/10.1016/j.jtcvs.2015.06.033
}

Depending on the size and location of the tumor, a patent left internal thoracic artery (LITA) to coronary artery bypass graft (CABG) can be technically intimidating to a thoracic surgeon hoping for an R0 resection with a left upper lobectomy. Dr Wei and colleagues ${ }^{1}$ at the University of Alabama are to be congratulated for their description and excellent results on successfully completing anatomic lung cancer resections of the left upper lobe in 28 patients who previously underwent CABG with LITA grafts. In fact, the surgical literature implies that we are batting 1000 when it comes to safety and effectiveness in this situation, even if the operations are performed with lessinvasive techniques, such as video-assisted thoracic surgery or the surgical robot. ${ }^{1-3}$ Furthermore, the authors are so confident in their technical ability to safely dissect the lung off the LITA that they perform their operations without an arterial line, central venous access, or a Foley catheter, not that those things necessarily would be life saving should the surgeon acutely disrupt a LITA to left anterior descending graft with the potential for acute cardiac ischemia and ventricular fibrillation.

In my mind, a patent LITA graft at the time of left upper lobectomy has the potential to pose a serious and potentially lethal threat to the thoracic surgeon and patient no matter what the operative approach. Although the authors suggest potential strategies for repairing and recovering from an injury to what is usually the most important coronary graft, the scenario of a disrupted coronary artery graft in a reoperative field while working in the left lateral decubitus position without easy exposure and access to cardiopulmonary bypass to is be avoided at all costs. The authors skillfully and successfully accomplished this.

The keys to success in this clinical scenario seem obvious but are not to be underestimated. The authors provide a logical and thorough algorithm for both evaluating and surgically treating patients with left upper lobe lesions who have previously undergone CABG with a LITA. Although only $86 \%$ of patients in this series underwent cardiac stress

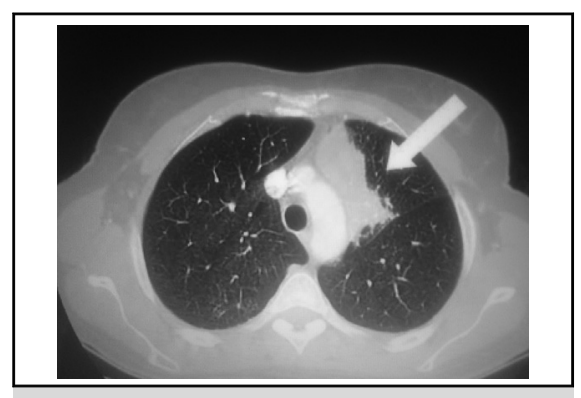

With a patent ITA graft, tumor location and size are key when planning left upper lobectomy.

\section{Central Message}

Left upper lobectomy after previous CABG with patent ITA grafts can be safely performed with thoughtful planning and careful technique.

See Article page 531.

testing before operation, it would seem that this should be mandatory in this situation, followed by coronary angiography should the patient be symptomatic or ischemic. Computed tomography angiography is useful to identify the anatomic location of the internal thoracic artery (ITA) graft relative to the lung and tumor, and can assist in operative planning. I would agree with the authors that the ability to review the previous $\mathrm{CABG}$ operative report is important although not always realistic, even in this era of electronic medical records. Although all of the ITA grafts

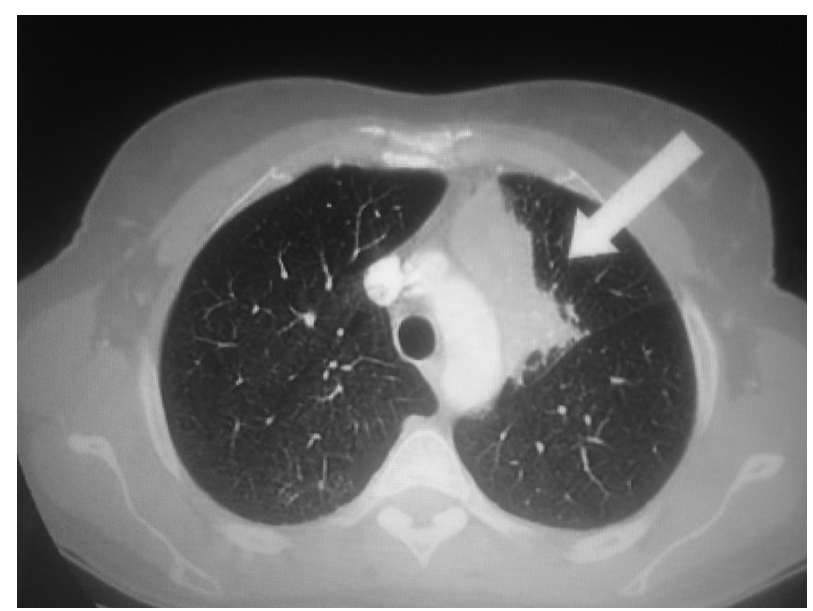

FIGURE 1. Large tumors that are medial and potentially involving a patent ITA graft may be a contraindication to resection. 
in this series were pedicle grafts that are thicker and relatively easily identified by the presence of surgical clips, skeletonized ITA grafts are becoming more popular and may be more difficult to identify at the time of pulmonary resection. The authors successfully dissected all but 2 left upper lobes completely off of the ITA graft despite the presence of significant adhesions in almost all, leaving a wedge of lung attached in only 2 patients. Although they describe the potential utility of using the surgical robot to perform lobectomies in this situation, this is clearly an advanced application of surgical robotics and a testament to their skill.

The authors neglected to discuss the types of patients who might not be candidates for left upper lobectomy or anatomic resection in the presence of a patent LITA graft. In fact, 2 of their patients had preoperative radiation therapy. I would propose that particularly large, medially situated tumors or tumors that are adherent to the LITA are potentially unresectable (Figure 1). Unfortunately, that can be difficult to predict on the basis of preoperative imaging. Regardless, Dr Wei and colleagues ${ }^{1}$ have thoughtfully provided a comprehensive roadmap for evaluating and safely operating on patients with left upper lobe tumors and patent coronary grafts.

\section{References}

1. Wei B, Broussard B, Bryant A, Linsky P, Minnich DJ, Cerfolio RJ. Left upper lo bectomy after coronary artery bypass grafting. J Thorac Cardiovasc Surg. 2015; 150:531-5

2. Funaki S, Inoue M, Shigemura N, Okumura N. Thoracoscopic lobectomy for lung cancer after coronary artery bypass grafting using internal thoracic artery. Interact Cardiovasc Thorac Surg. 2012;15:928-9.

3. Shah AA, Worni M, Onaitis MW, Balderson SS, Harpole DH, D'Amico TA, et al Thoracoscopic left upper lobectomy in patients with internal mammary artery coronary bypass grafts. Ann Thorac Surg. 2014;98:1207-12. 